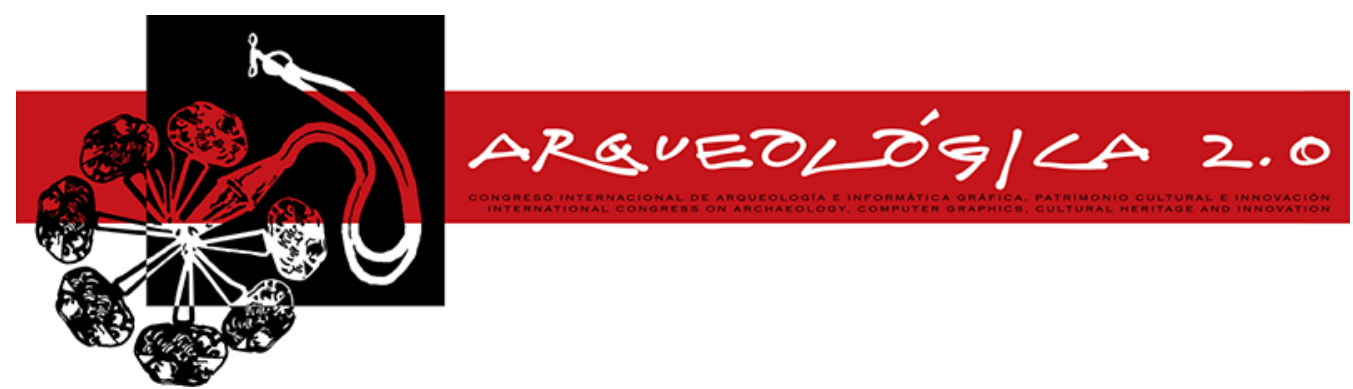

Proceedings of the $8^{\text {th }}$ International Congress

on Archaeology,

Computer Graphics,

Cultural Heritage and Innovation

'ARQUEOLÓGICA 2.0'

in Valencia (Spain),

Sept. 5-7, 2016

DOI: http://dx.doi.org/10.4995/arqueologica8.2016.2987

Received: 04/03/2016

Accepted: 04/04/2016

\title{
DOCUMENTACIÓN Y ANÁLISIS DE PIEZAS ARQUEOLÓGICAS DEL MUSEO DE BURRIANA MEDIANTE EL USO DE RX DIGITAL
}

\author{
RECORDING AND ANALYSIS OF ARCHAEOLOGICAL ARTEFACTS OF BURRIANA MUSEUM BY USING \\ DIGITAL RX \\ Jose A. Madrid ${ }^{\mathrm{a},}$, Jose Manuel Melchor ${ }^{\mathrm{b}}$ \\ a Instituto Universitario para la Restauración del Patrimonio, Universidad Politécnica de Valencia, Camino de Vera s/n, 46022 Valencia, \\ España. imadrid@crbc.upv.es \\ ${ }^{\mathrm{b}}$ Departamento de Geografia, Historia y Arte, Universitat Jaume I de Castelló, Av. Vicente SosBaynat s/n, 12071 Castellón, España. \\ melchor@uji.es
}

\begin{abstract}
:
This paper is the result of the research conducted on more than 200 archaeological artefacts from the Museum of Burriana as a result of 6 years of scientific collaboration between the Museum and the Instituto Universitario para la Restauración del Patrimonio of the Universitat Politècnica de València. Digital X-rays Technology has been used on these artefacts. This technique has allowed achieving valuable information in different aspects of the artefacts: from its content (in the case of well-preserved specimens) to technical manufacturing, or analysis of evidence of previous restoration interventions. The application of Digital X-ray Technology has shown a number of important benefits; not only at the economic level and data manipulation, but also allowing as data collectors that can be further processed and thereby obtain outcome. These results can be used into different 2D or 3D formats.
\end{abstract}

Key words: digital X-ray, digital archaeology, pieces, restoration, documentation, Burriana.

\section{Resumen:}

Este trabajo es fruto de la investigación llevada a cabo en más de 200 piezas arqueológicas del Museo de Burriana como resultado de los 6 años de colaboración científica entre el Museo y el Instituto Universitario para la Restauración del Patrimonio de la Universitat Politècnica de València. Usando en éste la tecnología digital en los registros radiográficos. Esta técnica ha permitido lograr una valiosa información en diferentes aspectos de las piezas: a partir de su contenido (en el caso de objetos bien conservados) para la comprensión en sus métodos de fabricación, o el análisis de la evidencia de anteriores intervenciones de restauración. La aplicación de la tecnología de digital en la radiografía ha demostrado una serie de importantes beneficios; no sólo en el nivel de la manipulación del registro y de tipo económico, sino que también permite que los datos obtenidos que se pueden procesar mejor y así poder conseguir el mejor resultado. $Y$ estos pueden ser utilizados en la formación de imágenes tanto 2D como 3D.

Palabras clave: arqueología virtual, arqueología digital, ciber-arqueología, patrimonio cultural, documentación, reconstrucción 3D

\section{Introducción}

Desde 2010, el Instituto Universitario para la Restauración del Patrimonio de la Universitat Politècnica de València y el Museo Arqueológico Municipal de Burriana vienen colaborando en la aplicación de los Rayos $\mathrm{X}$ en soporte digital a piezas arqueológicas. Fruto de esta cooperación ha sido el análisis de más de un centenar de artefactos (básicamente de tipo cerámico y de metal) actualmente depositados en el citado museo, tanto en sus almacenes, como en su exposición permanente.

El objetivo de esta investigación ha consistido en la documentación de materiales arqueológicos buscando el establecimiento de un protocolo de aplicación genérico a este tipo de piezas, cuyo resultado sea la obtención de resultados científicos que no se podrían obtener por otros medios de análisis físico no invasivo (Madrid y Ramírez 2011).

*Corresponding Author: Jose A. Madrid, jmadrid@crbc.upv.es 
En este caso concreto, la gran ventaja que presenta el uso de la radiografía en soporte digital es la facilidad de manipulación, consulta y archivo de las imágenes obtenidas, además de la posibilidad que ofrecen en futuros tratamientos digitales e informáticos sobre los datos actualmente obtenidos, y que ampliarán el espectro de futuros estudios.

\section{Los yacimientos arqueológicos}

Los trabajos se han llevado a cabo sobre diversos yacimientos (Fig. 1) y a continuación haremos una breve descripción de cada uno de ellos.

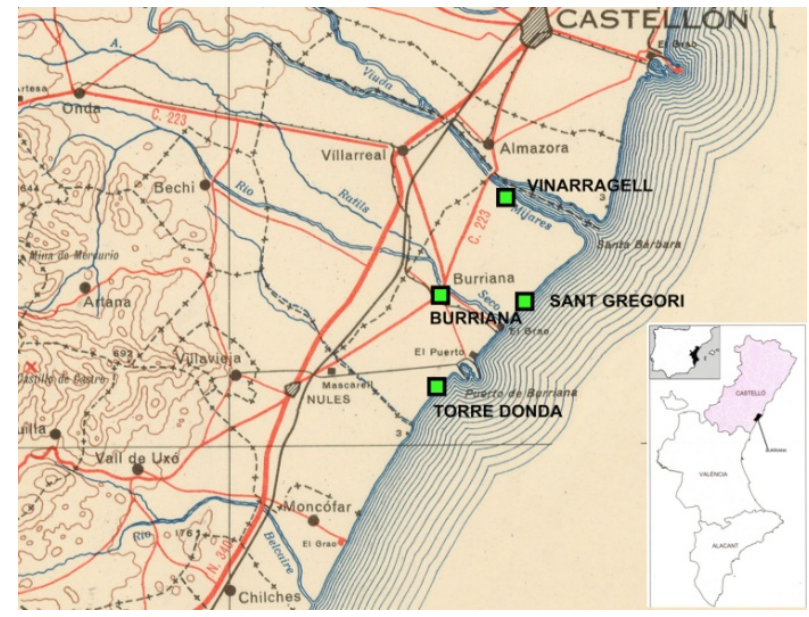

Figura 1: Plano de situación de los yacimientos citados en el texto.

\subsection{Centro Histórico de Burriana}

La ciudad de Burriana tiene su origen en época musulmana, y aparece reflejada en las escasas crónicas árabes que describían las ciudades a lo largo del camino, siendo la más antigua conocida la del historiador cordobés Ahmad ibn Muhammad al-Razi (887 - 955 d.C.). Sin embargo, no podemos hablar de Burriana como enclave urbano y fortificado con certeza hasta el siglo $\mathrm{XI}$, cuando empieza un largo periodo de inestabilidad con las invasiones almorávides y los ataques del Cid; además la propia técnica constructiva de la muralla musulmana apunta a una influencia del norte de África. La ciudad es conquista en el año 1233 por el monarca aragonés Jaume I, lo que produjo importantes cambios en la ciudad, que finalmente llevaron a un lento e inexorable proceso de decadencia que culminaría en el siglo XVII (Melchor 2011).

La arqueología urbana se desarrolló de forma esporádica desde principio del siglo XX entre el coleccionismo y el interés de aficionados, hasta que a finales de la misma centuria se amplía de forma muy importante la cantidad de excavaciones. Eso permitió al Museo Arqueológico Municipal de Burriana contar con un importante acervo de piezas medievales tanto en su depósito como en sus vitrinas.

\subsection{Villa romana de SantGregori}

Se trata de una villa romana situada en el término municipal de Burriana. La intervención desarrollada en Sant Gregori, en una colaboración entre la Universitat Jaume I, el Museo de Burriana y la Universitat
Politècnica de València, prosigue en la actualidad en la parte residencial de la villa situada en su extremo noreste, que ocupa la parte más cercana al agua (aproximadamente a $80 \mathrm{~m}$ de la costa actual) y que llegaría a contactar originalmente con el mar. La villa se desarrolla mediante un peristilo, con un gran estanque rectangular con orientación Norte-Sur y paralelo a la costa. Alrededor de él aparecen una serie de habitaciones con pavimento de opus caementicium, pero presuponemos que originariamente sería un pequeño espacio abierto ajardinado (Melchor 2013).

Hasta el momento, y a falta de futuras campañas de excavación, la intervención actual muestra una riqueza material considerable, pues además de una gran cantidad de mármol de muy distintas variedades, lapis specularis, agujas de hueso, vidrio, útiles de pesca, teselas, pintura mural, etc. se está recuperando un amplio conjunto de restos cerámicos. Todo ello apuntaría al momento de auge del asentamiento, entre el final o mediado del siglo I d. C., y una reforma y reutilización de parte de sus estructuras, quizá alrededor del siglo II d. C. Aún no podemos señalar el momento de abandono de la villa, pero los materiales encontrados por ahora hablan de una ocupación intensa por lo menos hasta mediado el siglo III d. C. y algunos indicios apuntan a una pervivencia hasta el siglo IV d. C. (Ferrer et al. 2013)

\subsection{Poblado ibero-romano de Torre d'Onda}

Este yacimiento se encuentra en la costa de Burriana y sus primeros hallazgos se remontan a principios del siglo $X X$, pero no fue hasta la década de los 80 , de ese mismo siglo, cuando empezó a ser objeto de excavaciones arqueológicas y que no tuvieron continuidad hasta el siguiente. En ellas se detectaron la existencia de calles, departamentos y muros de contención de un poblado de raíces iberas, con importante presencia de materiales itálicos y púnicos.

Lamentablemente buena parte del yacimiento se encuentra bajo construcciones actuales. Fruto de las intervenciones es una abundante colección de elementos cerámicos, y en menor cantidad de otro tipo de materiales. Probablemente nos encontremos ante un importante yacimiento dedicado prioritariamente al comercio marítimo, que tuvo su auge entre el siglo III a.C. y el cambio de Era (Melchor 2013).

\subsection{Poblado protohistórico de Vinarragell}

El yacimiento protohistórico de Vinarragell, incoado Bien de Interés Cultural por su extraordinaria contribución para conocer el proceso de iberización en tierras valencianas, situado en la ribera derecha del río Mijares a $80 \mathrm{~m}$ de su cauce actual y a $3,5 \mathrm{Km}$. de su desembocadura. Se trata de un pequeño montículo de cerca de $3,5 \mathrm{~m}$ de altura de forma irregular, con un diámetro entre 80 y $60 \mathrm{~m}$.

Se trata de un yacimiento de excepcional importancia para el conocimiento del periodo protohistórico, y por ello es Monumento Histórico Artístico del año 1985. Las excavaciones arqueológicas no se iniciaron hasta la década de 1960 , si bien el yacimiento ya era conocido de antiguo. Tras diversas campañas de excavación en Vinarragell, se sistematizan sus diversos horizontes culturales y de hábitat del siguiente modo: Hierro I, 
Cultura Ibérica, Romanización y Edad Media (Mesado 1988). No se realiza ninguna publicación con nuevos datos desde 1988, aunque con motivo de las obras del gasoducto Castellón-Valencia en 1991 y en 2008 se realizan intervenciones arqueológicas que indican que el yacimiento se extendería hasta el cauce del río Mijares y contaría con una necrópolis musulmana en su espacio inmediato (Melchor 2013).

Ya desde el año 2014 se han retomado los trabajos en el yacimiento mediante un equipo multidisciplinar formado por el Área de Historia Antigua de la Universitat Jaume I, el Museo de Burriana y el Servicio de Investigaciones Arqueológicas y Prehistóricas de la Diputación de Castellón.

\section{Marco de la investigación}

Los objetivos marcados en un primer momento consistían en el análisis de algunos aspectos genéricos de los materiales, tanto de forma individual como en su conjunto. Estos los podemos unir en los siguientes apartados, destacado en cada uno los casos más significativos detectados hasta el momento:

\subsection{Materiales sin intervenir}

Este grupo está formado por aquellos materiales extraídos del yacimiento y sobre los cuales se obtiene la imagen radiográfica sin haber recibido ningún tratamiento previo, ni tan siquiera la limpieza de los mismos.

En estos casos se ha podido apreciar claramente el interior de la pieza y su contenido. En algunos ejemplos como la lucerna romana del dextrarum iunctio (Fig. 2) extraída en el yacimiento de Sant Gregori en la campaña del año 2011 (Ferrer y Benedito 2012), se obtuvo una importante información de los depósitos de tierra en su interior, ya que la pieza apareció prácticamente intacta, pero en un contexto de las zanjas del siglo XVIII que afectaban buena parte del yacimiento (Melchor 2013).

Mediante los Rx se pudo observar cual había sido el proceso de colmatación por sedimentos del interior de la pieza, y se constató que originariamente se encontraba boca abajo al ser abandonada en época romana, lo que sumado al impacto que presentaba en la piquera (único daño reseñable) podemos suponer que sufrió una caída desde una superficie poco elevada, quedando en posición invertida sobre el suelo de la habitación de la villa, desde donde fue posteriormente extraída por las zanjas realizadas en época Moderna.

Otros casos, ya más habituales en la investigación arqueológica, como es el análisis de materiales férreos extraídos de la misma excavación de Sant Gregori (Fig. 3). En este caso los Rx fueron sin duda una importante herramienta, ya que permitieron, mediante el claro discernimiento entre el óxido y el núcleo metálico, hacer una selección de los materiales que presentaban un mejor estado de conservación, cara a proceder a su limpieza y consolidación, permitiendo reducir costes y obtener una mayor rentabilidad museográfica, pues se aseguraba intervenir sobre piezas importantes.

Pero además se obtuvo una valiosa información científica, ya que los resultados de los Rx permitieron clasificar piezas sin tener que proceder a su limpieza, lo cual no solo evitaba riegos para su integridad, sino que además aportaba una imagen mucho más aproximada a lo que había sido el original.
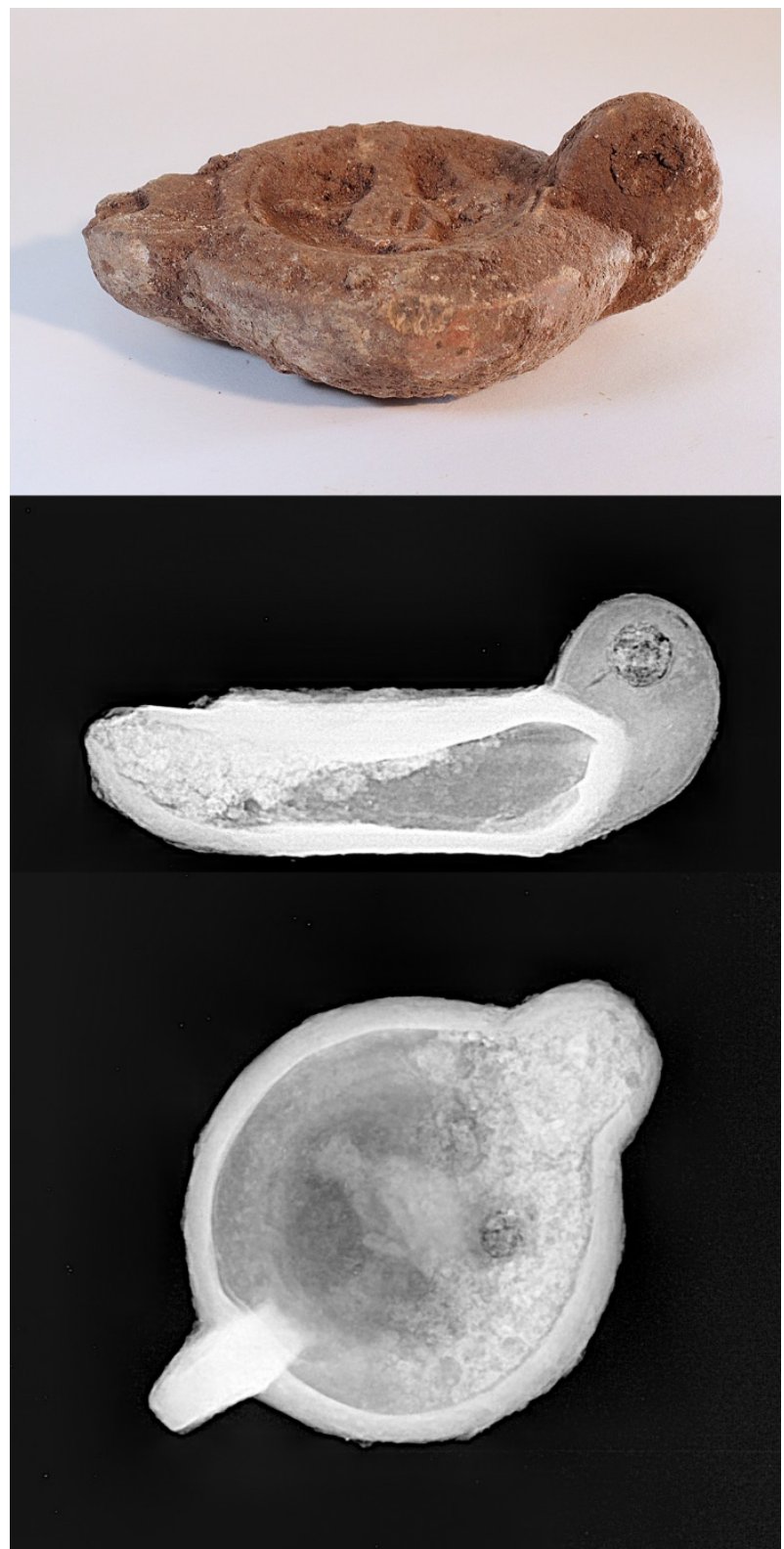

Figura 2: Lucerna romana del dextrarum iunctio y su Rx.

\subsection{Antiguas intervenciones}

Al tratarse de un museo con una larga trayectoria, las piezas que posee en sus fondos antiguos han sufrido distintas intervenciones de consolidación y restauración a lo largo de los años, no todas documentadas al uso y muchas con criterios hoy antiguos (Pasíes et al. 2011) actualmente poco acordes con los razonamientos museográficos recientes.

Como resultado de ello en el museo nos encontramos con piezas que han sufrido intervenciones antiguas importantes, que enmascaran y confunden los fragmentos originales y las reintegraciones. A la hora de tomar decisiones respecto a recuperar estas piezas con criterios nuevos y museográficamente más aceptables, la imagen radiográfica se muestra como una 
herramienta fundamental, ya que permiten diferenciar claramente que porcentaje de original tiene la pieza, además de su estado de conservación y cohesión.

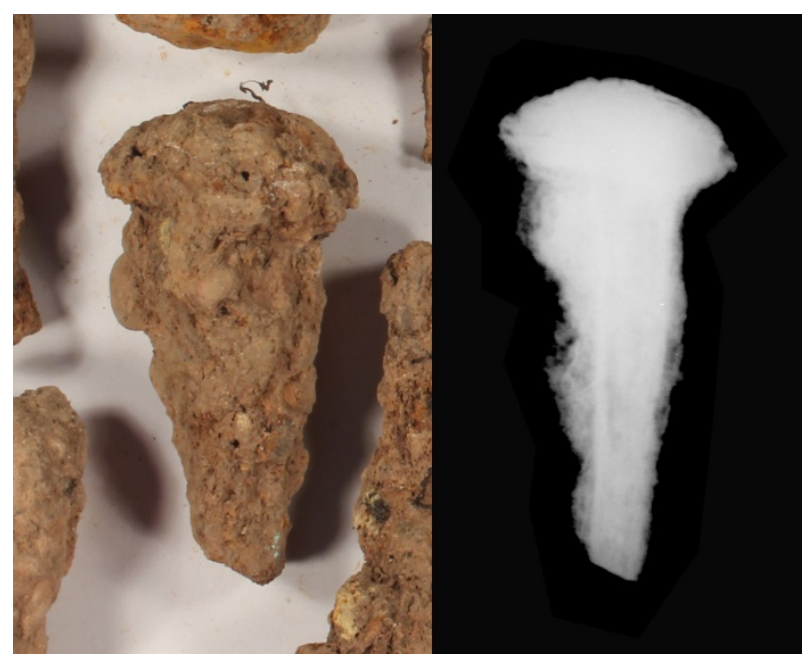

Figura 3: Material férreo del yacimiento de Sant Gregori.

El ejemplo más claro lo tenemos en una pieza de vajilla Campaniense B del yacimiento de Torre d'Onda, concretamente una forma Lamboglia 1 (Arasa y Mesado 1997) recuperada en los años 70 del siglo XX. Esta, además de abundantemente reintegrada con fragmentos que a veces revestían el original, fue cubierta por una pintura negra mate que en algunos casos impedía distinguir donde empezaba el original y donde acababa la reintegración (Fig. 4).

Otro aspecto importante de este apartado de la investigación es el análisis de antiguas restauraciones (en el caso de que se traten de intervenciones completamente miméticas, las incluimos en otro aparato de estudio), como es el tema de la jarra romana de cerámica común oxidante y probablemente de cronología entre los siglos I y III d. C., procedente de Mérida. Lamentablemente no existe información sobre cómo esta pieza llega al museo de Burriana, pero suponemos que vendría en el mismo contexto de los años 70 del siglo $X X$ en que también fueron traídos más materiales de origen extremeño, como ungüentarios de vidrio, cerámicas de paredes finas o una estatua de mármol, entre otras (Fig. 5).

En este caso se pudo comprobar el uso de alambres, cómo elemento sustentante de las reintegraciones, elementos que sería imposible documentar de forma correcta si no fuera mediante el uso de los Rx.

Esta información sin duda es muy valiosa a la hora de aportar datos a futuros estudios de analicen la evolución y la historia de las intervenciones de restauraciónconservación en España, ya que en este caso desconocemos si la pieza fue intervenida en origen.

\subsection{Material con intervenciones miméticas}

Como ya ha citado en el apartado de antiguas intervenciones, existen algunos casos en las que las piezas son objeto de restauraciones que intentan mimetizar el original y pasar desapercibidas. Este es otro de los temas en que los Rx aportan información esencial.
El primero de los casos es un ánfora tipo Dressel 1 del yacimiento de Torre d'Onda (Fig. 6), fruto de un hallazgo subacuático fortuito que ya se conocía desde principio del siglo XX. En su representación gráfica más antigua ya se observaba (Roca 1932:32) claramente que había sufrido una restauración. Sin embargo, en la actualidad prácticamente no se podía diferenciar ninguna intervención en esta pieza exhibida en el museo.

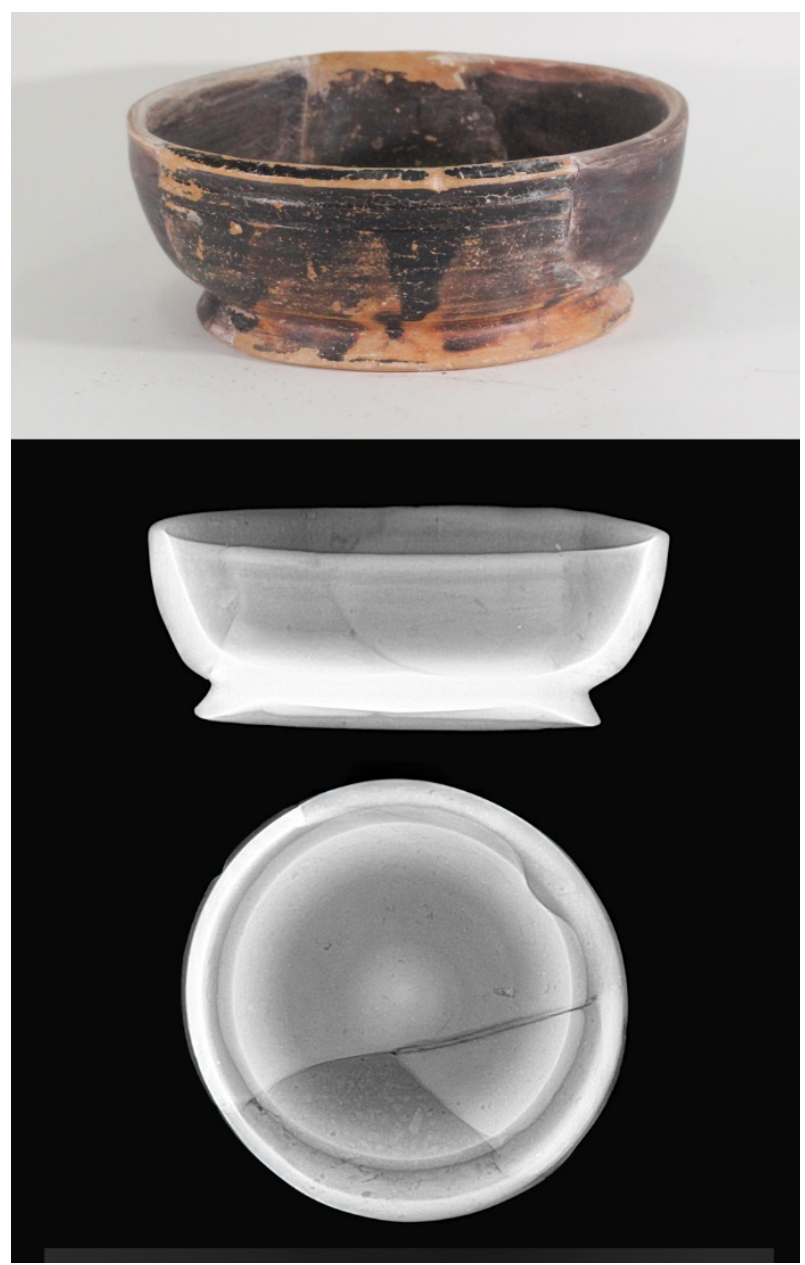

Figura 4: Campaniense B forma Lamboglia 1 de Torre d'Onda y su Rx.

Gracias al estudio radiográfico, no solamente se pudo documentar uno de los procesos más antiguos de restauración que se conservaban en el museo, sino que además se encontraron muchas más antiguas intervenciones en la pieza de las que no se tenía documentación, en parte por tratarse de una restauración muy antigua que podemos fechar aproximadamente en la primera década del siglo XX.

Otro caso destacado es la fíbula de bronce del yacimiento de Vinarragell (Fig. 7), perteneciente al periodo del Hierro I (Mesado 1988), de la cual no se tenía ninguna noticia sobre algún tipo de intervención sobre la pieza en los archivos del Museo de Burriana y que en una inspección visual aparentaba ser una pieza homogénea.

Pero a través de los $\mathrm{Rx}$ se comprobó que contaba con importantes intervenciones en buena parte del cuerpo original del artefacto, además de los añadidos de partes postizas. 
En ambos casos, como ya citamos anteriormente, no contamos con datos sobre las obras que se realizaron sobre las piezas, pero podemos suponer que las más recientes se ejecutaron a principio de la década de los 90 del siglo $\mathrm{XX}$, ya que fue el último periodo en que se llevaron a cabo de gran cantidad de intervenciones en material arqueológico.

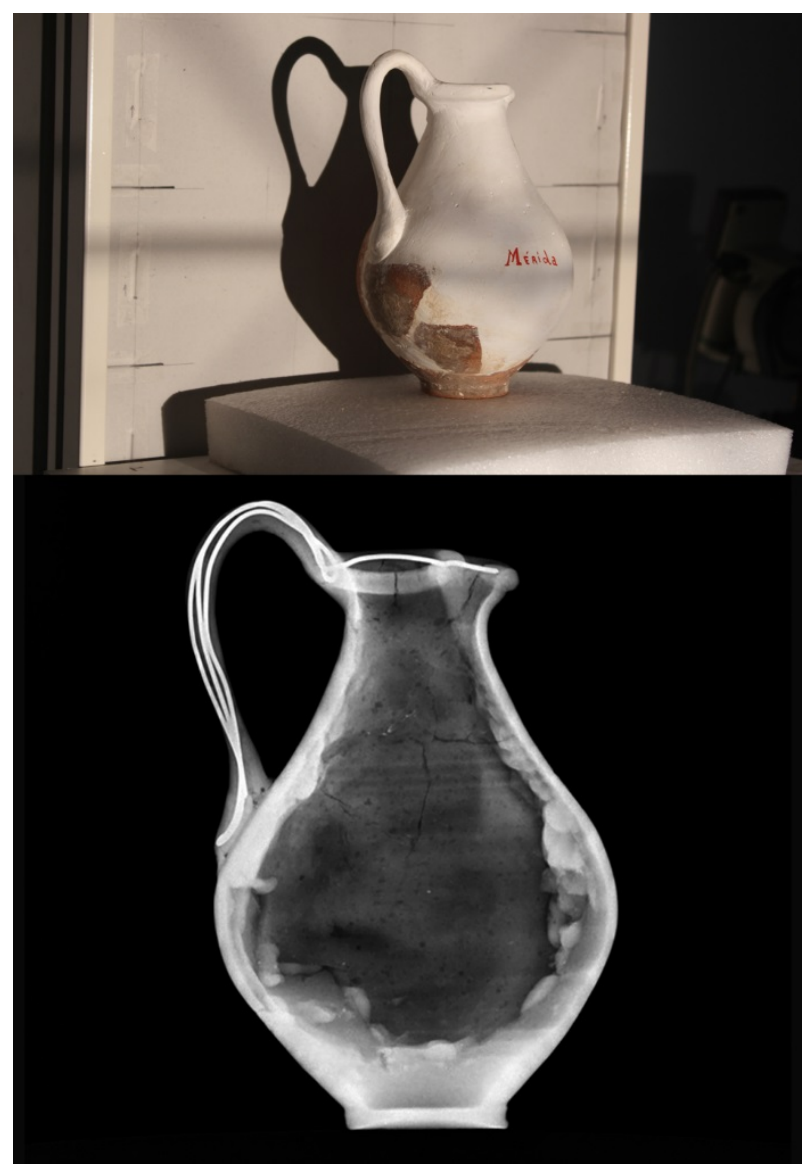

Figura 5: Jarra romana de Mérida del Museo de Burriana, vista frontal a través de su radiografía.

\subsection{Análisis de componentes y tecnología}

Entre los elementos analizados mediante Rx también tenemos interesantes ejemplos de materiales que ofrecieron significativos datos sobre sus componentes y tecnología de fabricación.

En la intervención desarrollada en la villa romana de Sant Gregori (Burriana), surgió la problemática de la identificación cronológica de materiales férreos (principalmente clavos y alcayatas) que se encontraban en fosas y zanjas que mezclaban materiales romanos y postmedievales. Gracias a la aplicación de Rx en estos materiales, la clasificación de los mismos fue bastante sencillas ya que la característica fabricación de estos elementos con núcleo hueco en época romana se diferenciaba claramente de los artefactos macizos de épocas más recientes (Fig. 8).

En el caso de los elementos cerámicos, tenemos la referencia de los materiales medievales del centro histórico de Burriana (Madrid y Ramírez 2011). Los Rx han permitido revelar con claridad la presencia de elementos metálicos en la decoración musulmana de las jarritas de cuerda seca o en los barnices cubrientes de otras piezas, además de importantes datos sobre la técnica de su fabricación, como por ejemplo el añadido de asas. (Fig. 9).

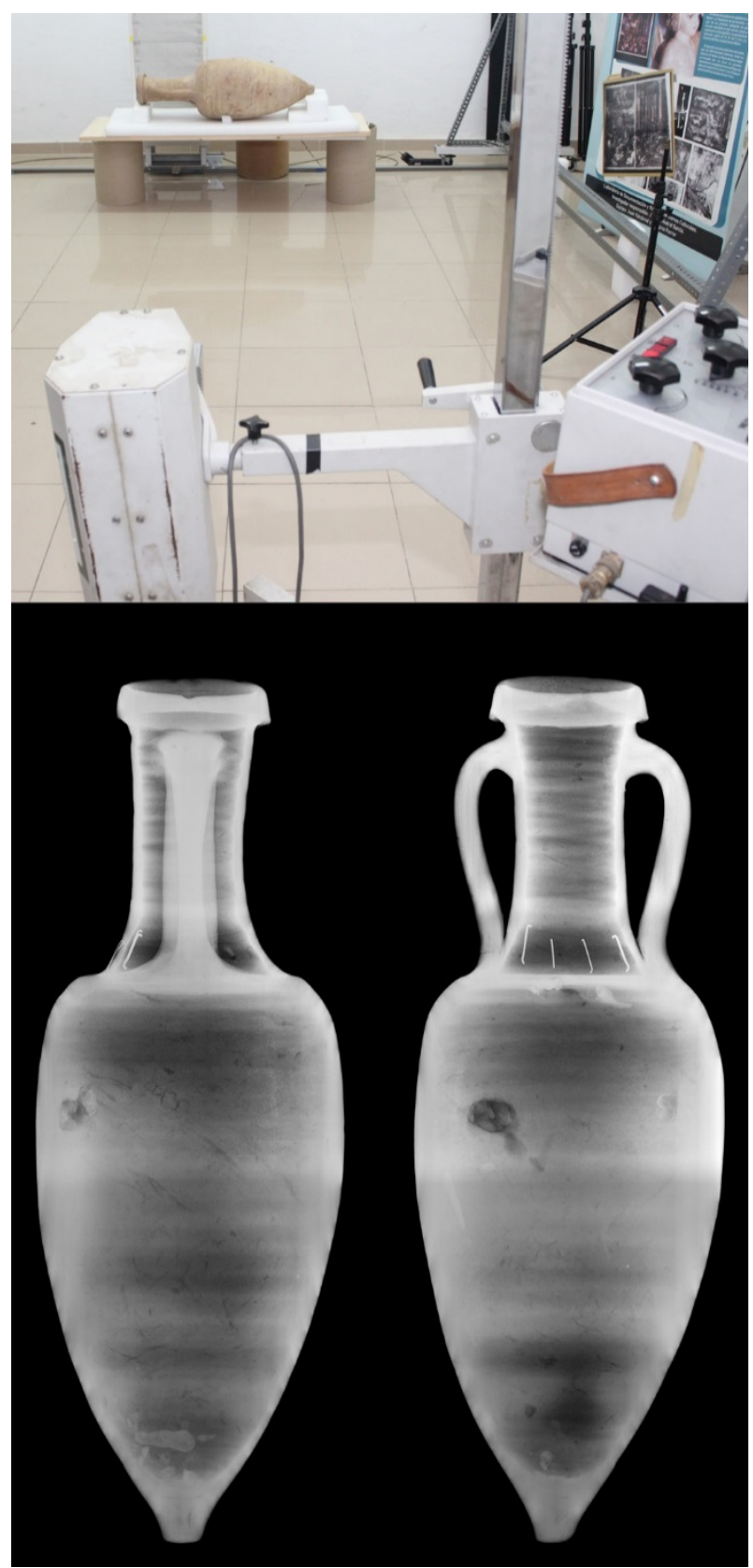

Figura 6: Ánfora Dressel 1 de Torre d'Onda y su Rx, a) ejecucción de la RX, b) vistas frontales en RX.

Este mismo procedimiento aportó información en el caso del aplique cerámico helenístico del yacimiento de Torre d'Onda (Fig. 10). En él se comprobó que se trataba de una cabeza de arcilla maciza, fabricada a molde, la cual se aplicó sobre la vasija y posteriormente se le añadió en su parte superior un asa trenzada.

Esto lleva a pensar que se utilizó un molde de la cabeza de una divinidad (probablemente la diosa Deméter) utilizada también en la fabricación de estatuillas de terracota conocidas como tanagrinas relacionadas con el culto, muy típicas del periodo helenístico; con lo cual nos encontraríamos con una pieza de excepcional interés en el contexto valenciano. 


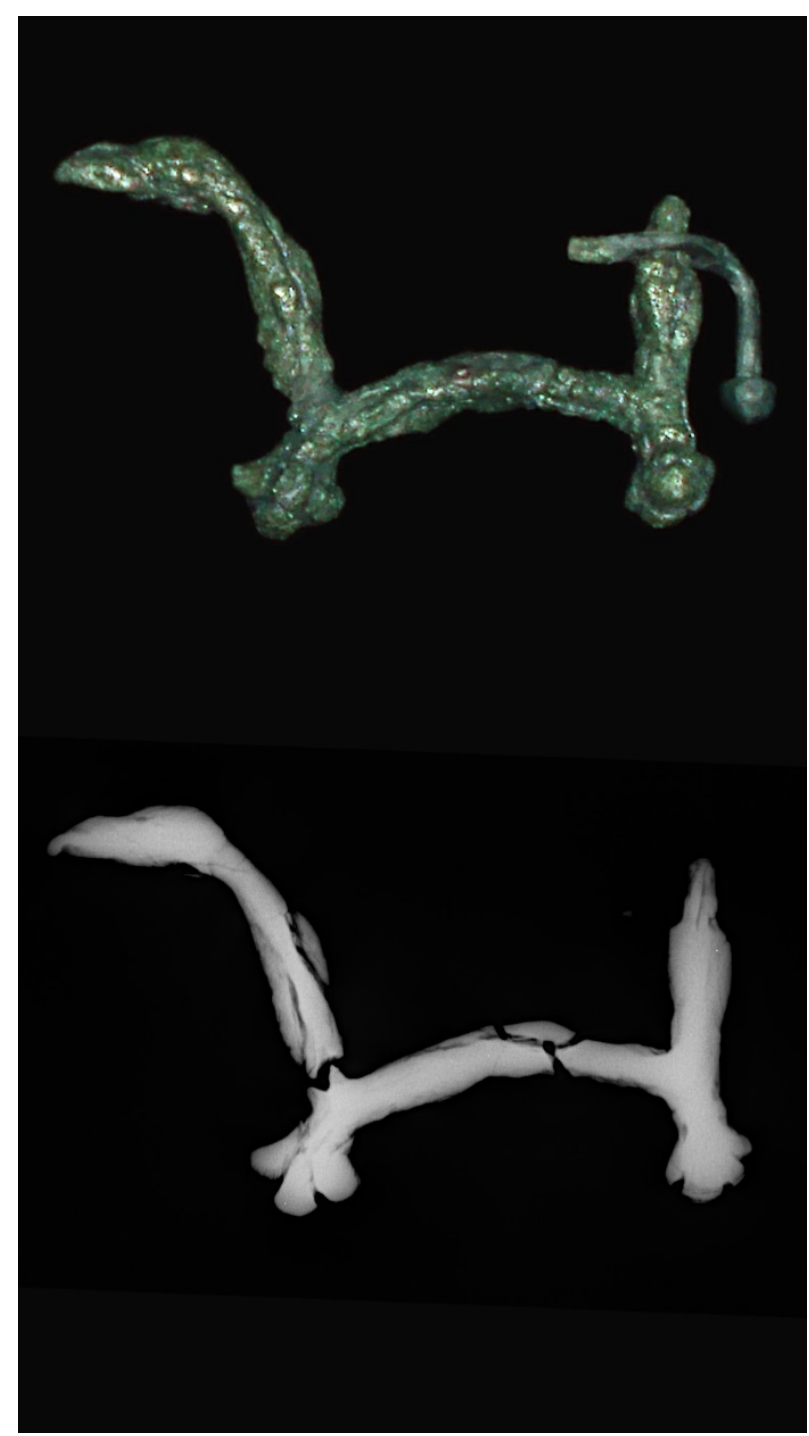

Figura 7: Fíbula del yacimiento de Vinarragell y su Rx.

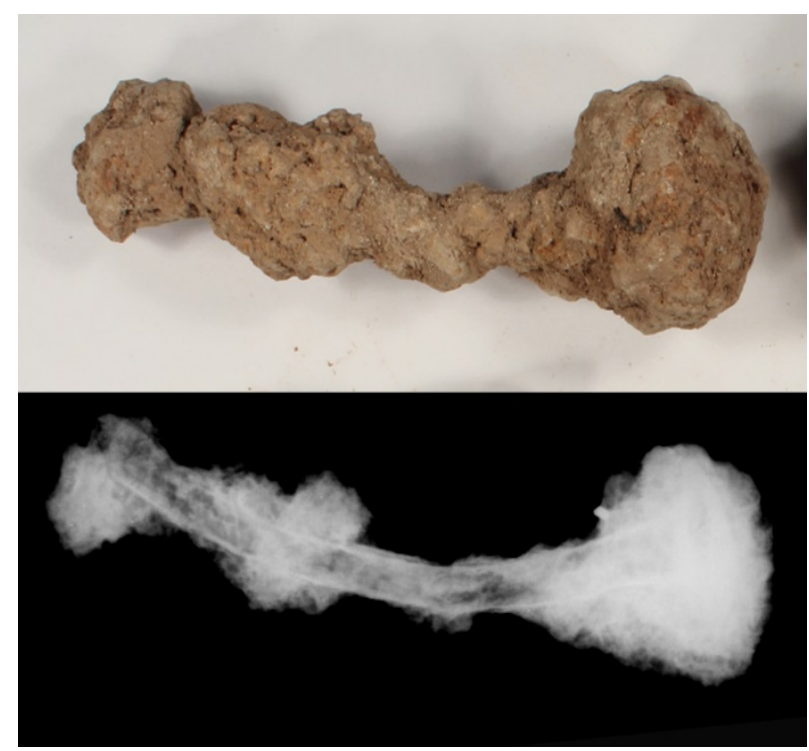

Figura 8: Material férreo romano y moderno de Sant Gregori.

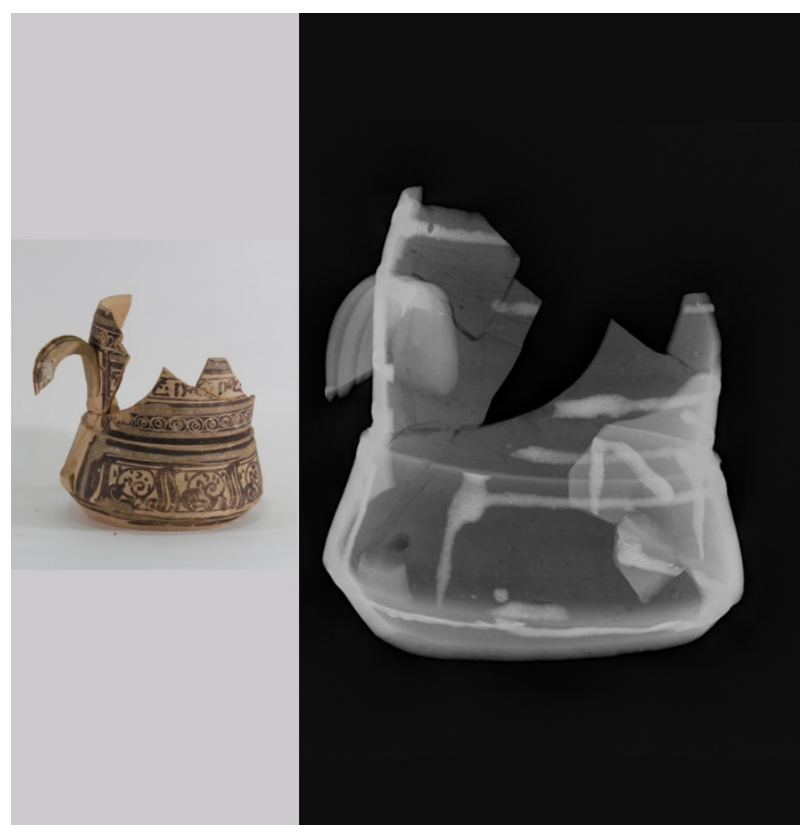

Figura 9: Material cerámico del centro histórico de Burriana.

\section{Tecnología de Rx aplicada a la investigación arqueológica}

La incorporación de la tecnología digital al estudio de rayos $X$ de bienes culturales está suponiendo en estos últimos años una pequeña revolución, sobre todo en los estudios arqueológicos. La tecnología del soporte digital en Rx ofrece solución a ciertas barreras propias del uso de los antiguos sistemas analógicos, como son los costes o la imposibilidad de ofrecer en muchos casos un registro adecuado. (Madrid 2014)

Con todo lo expuesto hemos podido constatar que poder implicar el uso de esta técnica en cualquier fase del estudio de una pieza, ya desde el mismo yacimiento o de su posterior tratamiento en taller, son ya un hecho. Ofreciendo en cada uno de esas etapas información relevante, tanto para su conservación, almacenaje o exposición.

\section{Proceso de la aplicación de los Rx en los artefactos arqueológicos}

En el presente estudio se ha empleado una fuente de rayos X TRANSXPORTIX 50尺, de la empresa General Electric, un detector de cámara de ionización y sistema de autorango, Ram Ion ${ }^{\circledR}$ de la empresa Rotem, más una procesadora automática de tipo $\mathrm{CR}$ de la empresa AGFA®. (Madrid 2006)

La procesadora es una estación de trabajo CR de radiografía indirecta $C R 30-X$ de la empresa $A G F A \otimes$. Este dispositivo se combina con el programa de identificación de imágenes y control de calidad AGFA® NX. La estación procesa las imágenes digitales obtenidas a través de los chasis CR MDT4.0T, también de $A G F A 囚$, con un formato de $35 \times 43 \mathrm{~cm}$ y un tamaño de matriz de pixel de $3480 \times 4248$.

Los parámetros usados para la obtención de las radiografías del estudio, como son voltaje $(\mathrm{kV})$ e intensidad ( $\mathrm{mA}$ ), se han ido adaptando a cada caso de estudio. Para ello se ha empleado el monitor de 
ionización, gracias al cual se establece la dosis (microSv) adecuada, dosis que marcara los valores de voltaje $(\mathrm{kV})$, intensidad $(\mathrm{mA})$ y tiempo de exposición más adecuados.

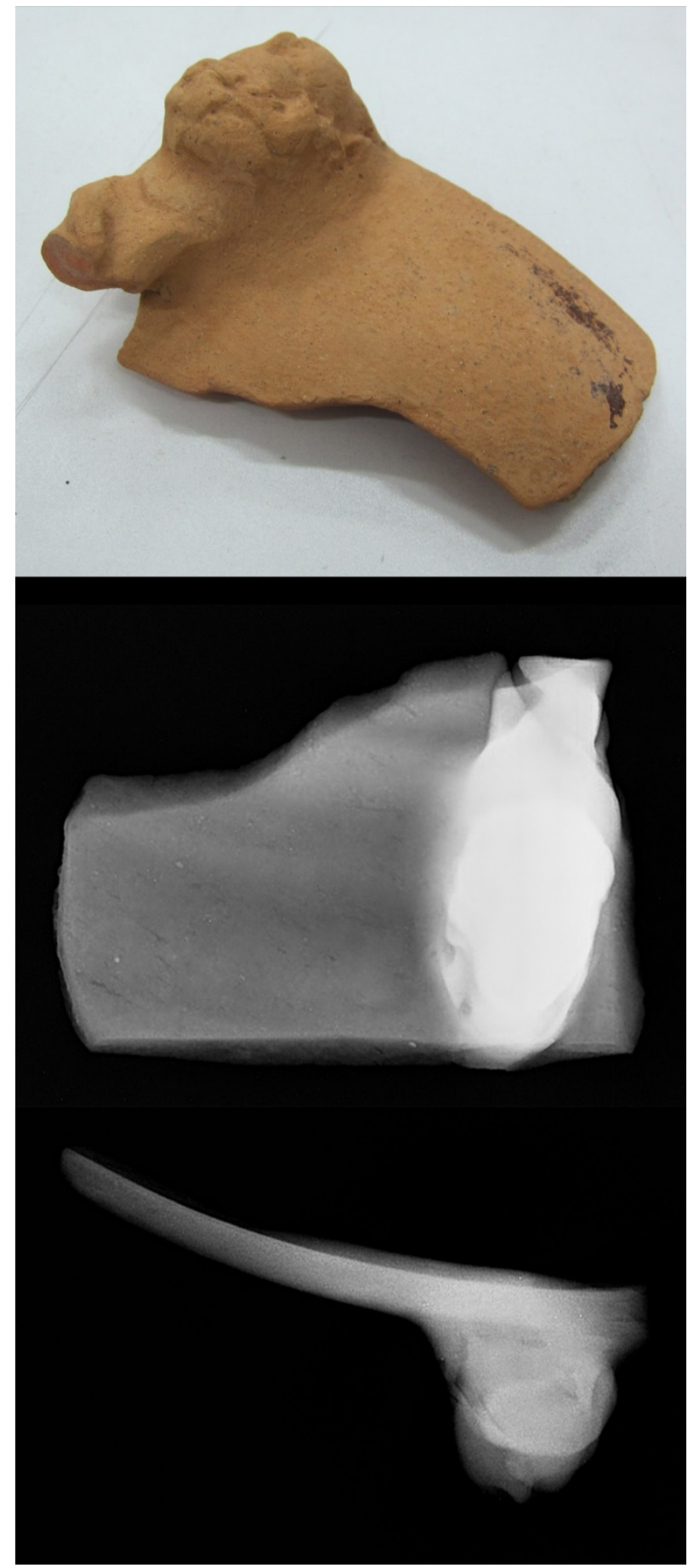

Figura 10: a) Aplique cerámico helenístico de Torre d'Onda, b) vista frontal en $R x, c)$ vista cenital en $R X$.

En el caso de Lucerna romana del dextrarum iunctio (Fig. 2) los parámetros fueron de $45 \mathrm{kV}, 20 \mathrm{~mA}$, con 3" de exposición, colocando la pieza a $100 \mathrm{~cm}$. La radiografía permite ver el estado en que se encuentra la orla y la representación de las dos manos derechas juntas sosteniendo un caduceo alado. Relieve que presentaba una gran cantidad de depósitos, debido a que la pieza no había sido intervenida, como se ha indicado.

El trabajo de estudio realizado para el conjunto de piezas del yacimiento de Sant Gregori fue más complejo. Fueron más de 40 placas radiográficas, con composiciones que oscilaban de 1 a 20 piezas en cada una de ellas. Nuestro objetivo fue hacer una selección objetiva de aquellas piezas que tenían más interés para su estudio o tratamiento posterior. Los parámetros se mantuvieron en un margen de voltaje que oscilo entre $50 \mathrm{kV}$ y $76 \mathrm{kV}$. En todos los casos se mantuvo constante la intensidad en $20 \mathrm{~mA}$, la exposición en 3" y la distancia entre foco e imagen de $100 \mathrm{~cm}$. (Fig. 3 y 8)

El estudio Campaniense B forma Lamboglia 1 de Torre d'Onda necesitó tan solo de $35 \mathrm{kV}, 20 \mathrm{~mA}$, con 3" de exposición en cada una de sus vistas, tanto frontal como cenital, colocando la pieza a $100 \mathrm{~cm}$. (Fig. 4)

El estudio realizado a la Jarra romana de Mérida (Fig. 5) sirvió de pretexto para realizar un estudio en un cuerpo de revolución. Para ello se obtuvieron las cuatro vistas de su eje sagital, más la referencia de su vista cenital. De esta forma los artefactos propios de la pieza no interfieren en la lectura de la misma. Todos los disparos se realizaron a la misma distancia de $100 \mathrm{~cm}$, con 42kV, 20 mA y 3" de exposición.

En el caso del Ánfora Dressel 1 de Torre d'Onda (Fig. 6) las medidas obtenidas a través del monitor de ionización (12,40 microSv por exposición) fueron fundamentales (Madrid 2011), debido a las dimensiones de la pieza $(85 \times 28 \times 28 \mathrm{~cm})$ lo que obligaba a colocar la fuente a $320 \mathrm{~cm}$ de distancia. La radiografía completa se construye a partir de 5 placas y los parámetros de las mismas fueron $72 \mathrm{kV}, 20 \mathrm{~mA}$ y 5 " de exposición.

La Fíbula del yacimiento de Vinarragell (Fig. 7), desde el punto de vista técnico también presenta un reto debido a la densidad del material constitutivo frente al empleado en las reconstrucciones posteriores. Los parámetros en este caso fueron $72 \mathrm{kV}, 20 \mathrm{~mA}$ y 5 " de exposición.

Para la jarra musulmana con decoración de cuerda seca (Fig. 9), como ejemplo de material cerámica del centro histórico de Burriana, los parámetros fueron $45 \mathrm{kV}, 20$ $\mathrm{mA}$ y 3 " de exposición manteniendo una distancia entre el objeto y el foco de $100 \mathrm{~cm}$.

Caso curioso fue el Aplique cerámico helenístico de Torre d'Onda (Fig. 10), pues siendo una pieza de terracota se tuvo que emplear un voltaje un tanto elevado, de $72 \mathrm{kV}$, para la obtención de un registro óptimo. El resto de parámetros fueron $20 \mathrm{~mA}$ y 3 " de exposición.

\section{Conclusiones}

En la actualidad, las ventajas de la aplicación de la radiografía digital en el campo de la arqueología son más que evidentes. Por un lado, está la vertiente puramente crematística, pues representa un menor coste económico respecto a la analógica, debido a que necesita una menor cantidad de soporte material y permite una mayor facilidad a la hora de analizar digitalmente los resultados, más la inmediatez en su obtención

Pero además es una herramienta muy valiosa para el análisis de materiales arqueológicos, pues permite 
reducir costes y agilizar el proceso de decisión a la hora de limpiar y restaurar piezas donde un examen visual no permite calibrar su verdadero estado, como en el ejemplo que exponemos referido a piezas con abundante cubierta de óxido.

La otra vertiente importante es la investigación científica de los materiales constituyentes de las piezas, ya que la manejabilidad de la radiografía digital permite clasificar objetos no visibles (por ejemplo los que se encuentran dentro de núcleos de óxido), obteniendo resultados a nivel de componentes, tanto en los casos donde los materiales estén compuesto por elementos metálicos ( $p$. e. la decoración en cuerda seca de época musulmana), como a nivel de unidades que presenten distinta respuestas a los $\mathrm{Rx}$, en este caso hablamos de los componentes de la pasta de cerámica con la superficie cubierta completamente por engobe, pintura, vidriado, etc. o de las partes de restauraciones antiguas no documentadas.

Finalmente debemos hablar del análisis de elementos estructurales, en la composición de piezas, que pueden aportar datos interesantes respecto a la tecnología cerámica, como es el montaje de las piezas o el uso de elementos añadidos y apliques, que, en algunos casos, como el ejemplo expuesto de la cabeza cerámica de Deméter, pueden ayudar al análisis estilístico y cronológico de la pieza.

Pero somos conscientes de que queda mucho camino por recorrer y que las posibilidades con la radiografía digital son muchas. Máxime si incorporamos la tecnología 3D y la posibilidad de la impresión de piezas.

Son ya algunos ejemplos los que estamos obtenido con la mezcla de la visualización en tres dimensiones de la pieza, más la incorporación de la imagen radiográfica. Imágenes que están facilitado la compresión de los objetos estudiados.

Como objetivo y líneas de futuro queremos indagar más en las posibilidades que estas técnicas nos pueden ofrecer, intentado que se lleguen a entender como referentes a la hora de la investigación, estudio y muselización de estos objetos.

\section{Referencias}

ARASA, F. y MESADO, N., 1997. La cerámica d'importació del jaciment ibéric de Torre d'Onda (Borriana - La Plana Baixa). Archivo de Prehistoria Levantina, XXII, pp. 375-408.

FERRER, J.J. y BENEDITO, J., 2012. La dextrarum iunctio y su representación en el registro arqueológico romano: la lucerna de Sant Gregori (Burriana - España). Millars, XXXV, pp.25-48. DOI:dx.doi.org/10.6035/Millars.

FERRER, J.J., MELCHOR, J.M. y BENEDITO, J., 2013. Sant Gregori. Un complejo arquitectónico de época romana en la costa de Burriana (España). Millars, XXXVI, pp.129-233. DOI:dx.doi.org/10.6035/Millars.

MADRID, J.A., 2006. Aplicación de la técnica radiográfica en la Conservación y Restauración de bienes culturales. Valencia. Universitat Politècnica de València.

MADRID, J.A., 2013. "Use of telemetry X-ray techniques in large-size pictorial works”. En Ge-conservación. n 5. pp 101109.

MADRID, J.A., 2014. Dos décadas de inspección radiográfica en España: retrospectiva y horizontes en un contexto de cambio tecnológico. Intervención. Revista Internacional de Conservación, Restauración y Museología, Escuela Nacional de Conservación, Restauración y Museografía-INAH. Año 5. Núm. 10, Julio-diciembre de 2014. pp. 8593.

MADRID, J.A. y RAMÍREZ, A.M., 2011. Radiografía digital en el estudio de piezas cerámicas. Estudio e interpretación de cerámica medieval procedentes del Museo Arqueológico Municipal de Burriana. En: J.M. MELCHOR, J. BENEDITO y T. PASIES, eds, La arqueología de la Buriyyana islámica a la Borrianacristiana. Conselleria de Governació de la Generalitat Valenciana, pp. 153-172.

MELCHOR, J.M., 2011. La arqueología como fuente de estudio para la Burriana medieval. En: J.M. MELCHOR, J. BENEDITO y T. PASIES, eds, La arqueología de la Buriyyana islámica a la Borriana cristiana. Conselleria de Governació de la Generalitat Valenciana, pp. 11-48.

MELCHOR, J.M., 2013. Diez años del Servicios Arqueológico Municipal de Burriana, Ayuntamiento de Burriana. 160 páginas.

MESADO, N., 1988. Nuevos materiales arqueológicos en el Pozo I del yacimiento de Vinarragell (Burriana, Castellón). Archivo de Prehistoria Levantina, XVIII Tomo II, pp. 287-328.

PASIES, T., PEIRÓ, M.A. y TEJERINA, D., 2011. La conservación-restauración en arqueología. Trabajos en el laboratorio del Museo Arqueológico de Burriana. En: J.M. MELCHOR, J. BENEDITO y T. PASIES, eds, La arqueología de la Buriyyana islámica a la Borriana cristiana. Conselleria de Governació de la Generalitat Valenciana, pp. 137-152.

ROCA, F., 1932. Historia de Burriana. Imprenta Hijos de Armengot. Castellón. 562 páginas 